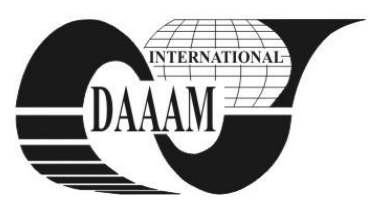

Annals of DAAAM for 2011 \& Proceedings of the 22nd International DAAAM Symposium, Volume 22, No. 1, ISSN 1726-9679 ISBN 978-3-901509-83-4, Editor B. Katalinic, Published by DAAAM International, Vienna, Austria, EU, 2011 Make Harmony between Technology and Nature, and Your Mind will Fly Free as a Bird

Annals \& Proceedings of DAAAM International 2011

\title{
VIRTUAL SIMULATION OF TURN-MILLING OPERATIONS IN MULTITASKING MACHINES
}

\author{
CALLEJA, A[maia]; FERNANDEZ VALDIVIELSO, A[sier]; LOPEZ DE LACALLE, L[uis] N[orberto] \& \\ FERNANDEZ, J[okin] T[omas]
}

\begin{abstract}
This paper explains a reliable methodology to be followed by multitasking machines in turn-milling operations. The main objective is to highlight the importance of virtual verification. The possibility of working at the same time with both heads, Bottom Turret and B-Axis Head, considerably increments the risk of collision. Virtual verification of this kind of operations is compulsory, taking into account that any collision could be catastrophic for the machine and for the part. This will assure that the order and the synchronicity between the different activities is the correct one, respecting the transference from one spindle to another.
\end{abstract}

Key words: multitasking, CAD-CAM, turn-milling, virtual verification

\section{INTRODUCTION}

Nowadays the structural complexity and the wide range of different movements of multitasking machines makes more difficult the programming of machining operations. Setting the correct order of the operations is of vital importance in order to save time, being desirable to check if a tool path is correct before cutting the actual component (Erik L.J. Bohez et al., 2003). To ensure that collisions are not happening, virtual verification needs to be carried out.

Firstly, it is worth mentioning that the CAD/CAM process of complex pieces is not an easy process. Defining a methodology that will ensure the reliability of the process could be really helpful. The first step will be choosing the CAD/CAM software, what is very important because some of them have many different integrated modules that will make the task easier for the user not having to change the software. Many of the actual CAM softwares bring the possibility of incorporating a virtual verification module where the virtual machine can be built. The programming of the CAM operations has to be carefully made taking into account the best strategies and at the same time the right order of the operations trying to optimize as much as possible. Once the CAD and the CAM of the part are defined and finished it is necessary to program the postprocessor of the multitasking machine. It is very important to pay special attention to the postprocessor that will make the data transfer from Apt Format (CAD) in ISO Format (Ghinea et al., 2010). Postprocessors are personally designed for each machine configuration and for each NC. They include information such as configuration, movements and axis limits of the machine and functions such as $\mathrm{G}$ and $\mathrm{M}$ of the NC. Finally, the CNC codes can be verified using virtual machine tool (Kriangkrai Waiyagan et al., 2009). When the CAM programs have been postprocessed, the next and final step is to virtually verify the different operations that will be carried out to obtain the final piece. The software requires some information that needs to be included, the CAD files of the real machine and its configuration, the type of $\mathrm{NC}$ and the postprocessed CNC programs of the part. From the virtual verification it is possible to obtain several conclusions that could lead to a better machining. There are many beneficial results offered in manufacturing engineering because it represents an object-oriented methodology for the modeling and simulation of a virtual manufacturing environment (Janus S.Liang, 2009).

\section{METHODOLOGY}

The proposed methodology has been followed to virtually verify the operations made in a turn-milling machine before real machining. In this case the first step has been the CAD design of a test part, whose geometry needs to be obtained making use of all the possibilities of the machine tool. After that, the CAM operations have been carefully programmed. For both CAD and CAM operations UGS software has been used. Afterwards, taking into account the characteristics of the machine, the number of axis, its configuration and limits, and the CNC functions, a personalized postprocessor has been programmed and its proper operation has been tested. For the last step, virtual verification, UGS software has been used. It is necessary to design the CAD of the machine and the tools and include them in the verification software to define the machine configuration. References, postprocessed CNC files and the type of CNC have also been included in the software. After previous steps have been followed, it has been possible to verify possible undesirable errors that have been modified until the virtual machining has reached real machining conditions. Many authors have study and concluded that virtual verification has several advantages, especially time and money saving (Parpala, 2009) (Sankar Jayaram et al., 2010). On one hand, it is possible to analyze and avoid machining collisions that could cause waiting times and incremental costs. The cost produced by the stop of the production and the reparation of the machine are two aspects that a correct virtual verification can avoid. On the other hand, the machining part will not be damaged resulting a part that meets all the demanded requirements. Not only that, but virtual verification could also compare the surface finish in order to determine whether it meets the requirements or not (Yingxue Yao et al., 2006).

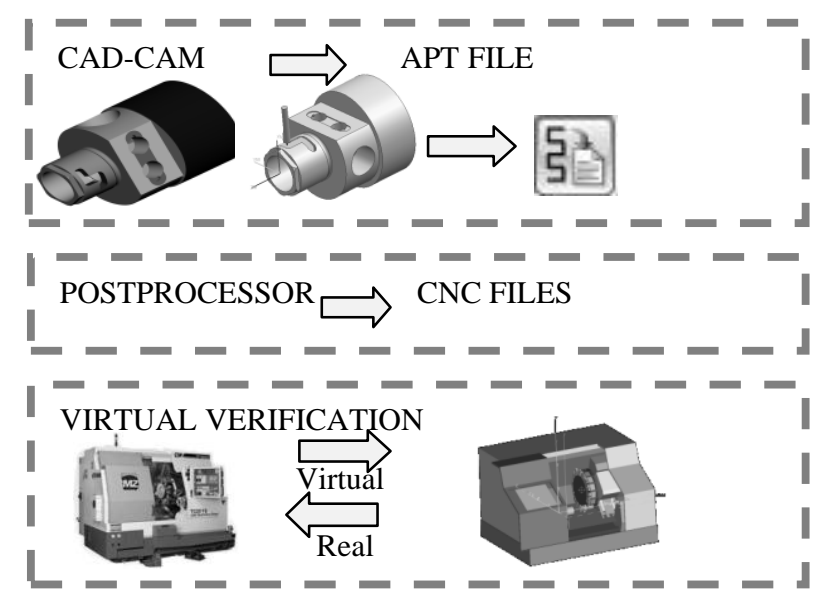

Fig. 1. Methodology 


\section{REAL APLICATION}

The methodology has to be followed to finally machine a real part that in this case is a prototype part for the aeronautical sector. The postprocessor for UGS has been particularly programmed for the machine tool available, that in this case is a mill-turn machining center TC25BTY from CMZ Machinery Group and the NC is a GE Fanuc Series 31i-model A. The $\mathrm{CAD}$ of the machine is progressively included in the machine verification module and the kinematics of the machine is defined. When a collision is found during the simulation process the corresponding CAM operation is corrected and the simulation is ran again to verify a no collision process.

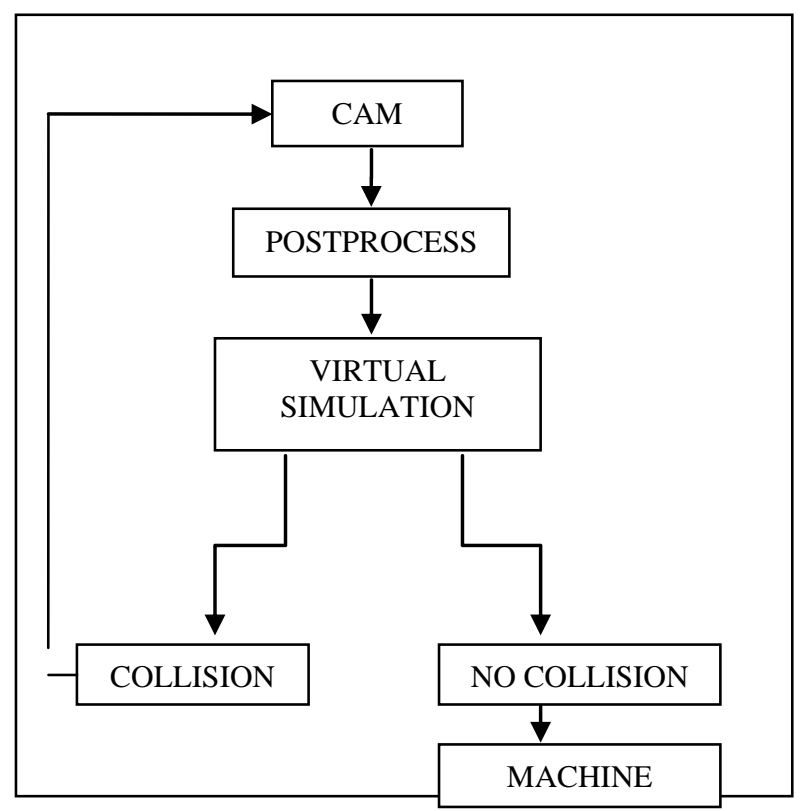

Fig. 2.Virtual verification process.

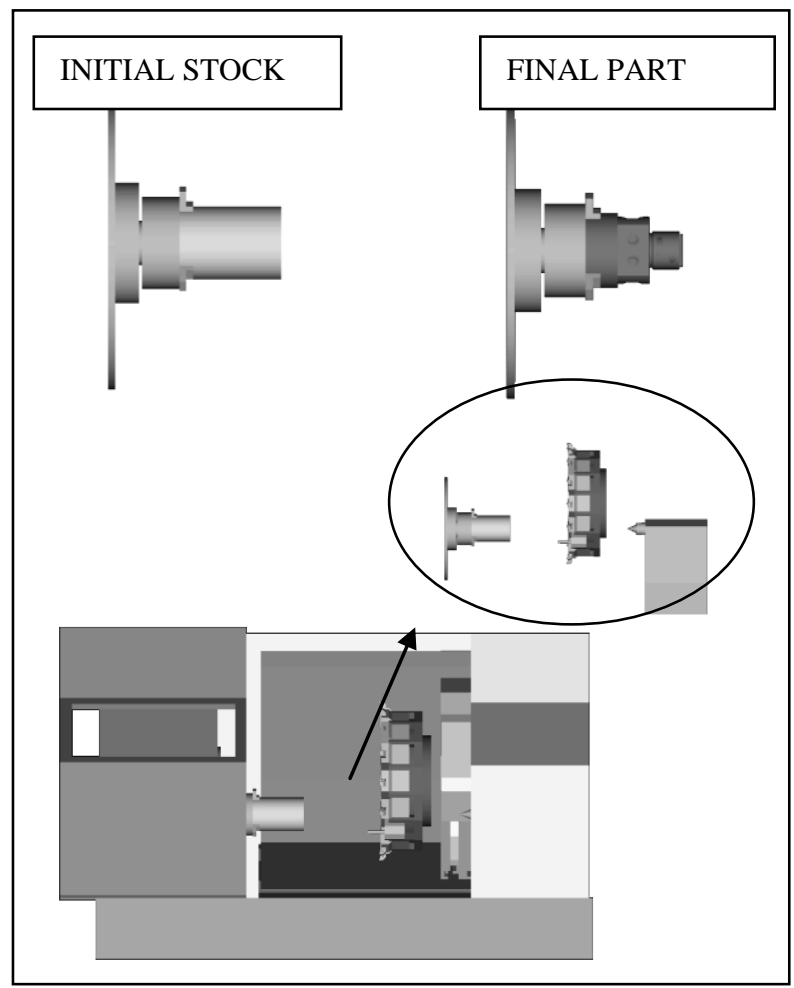

Fig. 3.Virtual machine tool

\section{FURTHER STEPS}

Further steps in the matter may be directed to meet the limitations of the actual research. A more detailed verification than the actual simulation in which more details of the machine could be included to obtain a more similar simulation to the real process. On the other hand, the representation of virtual workpiece that can characterize the machining error of workpiece is a key problem. Taking into account that virtual verification can also determine the finish surface accuracy, machining parameters could be adjusted, in relation to the results shown by the virtual simulation, in order to improve the final result. The prediction of errors caused by machining conditions such as wrong machining parameters that could lead to excessive forces or chatter conditions is the next step to take.

\section{CONCLUSION}

This paper shows the importance of using a reliable methodology for turn-milling operations when dealing with multitasking machines. Virtual verification of the machining process will reduce the risk of collision, resulting in a much more reliable process. The reduction of collisions at the same time will result in an economic benefit for the user because extra charges due to collision reparation and the production will not be stopped.

\section{ACKNOWLEDGEMENTS}

Thanks are addressed to the Basque Country Gobernment for the financial support and to Margune Etortek proFuture project. Special thanks to Adrián Rodriguez, Eduardo Sasía and Gorka Urbicain for the technical advices.

\section{REFERENCES}

Erik L.J. Bohez, Nguyen Thi Hong Minh, Ben Kiatsrithanakorn, Peeraphan Natasukon, Huang Ruei-Yun, Le Thanh Son. (2003). The stencil buffer sweep plane algorithm for 5-axis CNC tool path verification. ComputerAided Design, Vol.35, pp.1129-1142

Ghinea, M.; Dobrescu, T.; Nicolescu, A. F. \& Enciu, G. (2010). The Importance of a Postprocessor in Data Transfer from Apt Format (CAD) in ISO Format Used by Heidenhain iTNC 530, Annals of DAAAM for 2010 \& Proceedings of the 21st International DAAAM Symposium, 20-23rd October 2010, Zadar, Croatia, ISSN 1726-9679, ISBN 9783-901509-73-5, Katalinic, B. (Ed.), pp. 0347-0348, Published by DAAAM International Vienna, Vienna.

Janus S.Liang. (2009). An approach for generating a tasks schedule model. Int J Adv Manuf Technol, Vol.46, pp.737755.

Kriangkrai Waiyagan, E.L.J. Bohez. (2009). Intelligent feature based process planning for five axis millturn parts. Computers in Industry, Vol.60, pp.296-316

Parpala, L. F. (2009). How to Lower Cost and Time for Manufacturing in Virtual Enterprises, Annals of DAAAM for 2009 \& Proceedings of the 20th International DAAAM Symposium, 25-28th November 2009, Vienna, Austria, ISSN 1726-9679, ISBN 978-3-901509-70-4, Katalinic, B. (Ed.), pp. 0317-0318, Published by DAAAM International Vienna, Vienna

Sankar Jayaram, Hugh I Connacher, Kevin W Lyons. (1997). Virtual assembly using virtual reality techniques. Computer-Aided Design, Vol.29, No.8, pp.575-584, 1997

Yingxue Yao, Hang Zhao, Jianguang Li, Zhejun Yuan. (2006). Modeling of virtual workpiece with machining errors representation in turning, Journal of Materials Processing Technology, Vol.172, pp.437-444 